\title{
Pemberdayaan Usaha Garam Rakyat Dalam Meningkatkan Kualitas Garam Menggunakan Teknik Geomembran LDPE di Kelurahan Talise Kota Palu
}

\author{
Nelky Suriawanto ${ }^{1}$, Nurhayati ${ }^{2}$, Wendi Muhammad Fadhli ${ }^{3}$, M. Syahril ${ }^{4}$, Nivita Nanda Gabrela ${ }^{5}$ \\ ${ }^{1}$ Dosen Program Studi Ilmu Keperawatan, STIKes Widya Nusantara Palu, Kota Palu, Indonesia \\ 2,3,4,5 Mahasiswa Program Studi Ilmu Keperawatan, STIKes Widya Nusantara Palu, Kota Palu, Indonesia \\ Email: nelkysuriawanto@stikeswnpalu.ac.id
}

\begin{abstract}
Salt is an important commodity that is widely used from consumption to industry. Talise Village is the only salt-producing village in Palu City because the area is mostly located on the coast of Palu Bay. LDPE (Low Density Polyethylene) geomembrane technology is an empowerment program focused on increasing the production and quality of salt products and improving welfare by increasing the income of salt farmers. The purpose of this activity is to apply LDPE geomembrane technology to salt farmer groups in Talise in producing and improving the quality of SNI-standard salt as consumption salt and increasing awareness of salt farmers to use technology in managing their salt ponds. The method used is the stages of socialization, pre-production and production. The results of this activity program, namely the use of LDPE geomembrane technology on crystal tables, have increased the quantity and quality of salt for salt farmers in Talise Village, Mantikulore District, Palu City, Central Sulawesi. In addition, crop yields have increased threefold and harvest time is 3 to 4 days faster than conventional methods.
\end{abstract}

Keywords: Salt, Geomembrane, Low Density Polyethylene

\begin{abstract}
Abstrak
Garam merupakan komoditas penting yang banyak digunakan secara luas dari kepentingan konsumsi sampai dengan industri. Kelurahan Talise merupakan satu-satunya keluruhan di Kota Palu penghasil garam karena daerahnya sebagian besar berada di pesisir teluk Palu. Teknologi geomembran LDPE (Low Density Polyethylene) merupakan program pemberdayaan yang difokuskan pada peningkatan produksi dan kualitas produk garam serta peningkatan kesejahteraan dengan meningkatkan pendapatan petambak garam. Tujuan dari kegiatan ini yaitu menerapkan teknologi geomembran LDPE pada kelompok petani garam di Talise dalam memproduksi dan meningkatkan kualitas garam berstandar SNI sebagai garam konsumsi serta meningkatkan kesadaran petani garam untuk menggunakan teknologi dalam mengelola tambak garamnya. Metode yang digunakan yaitu tahap sosialisasi, praproduksi dan produksi. Hasil dari program kegiatan ini yaitu penggunaan teknologi geomembran LDPE pada meja kristal telah meningkatkan kuantitas dan kualitas garam petani garam di Kelurahan Talise Kecamatan Mantikulore Kota Palu Sulawesi Tengah. Selain itu hasil panen mengalami peningkatan tiga kali lipat dan waktu panen lebih cepat 3 sampai 4 hari dari metode konvensional.
\end{abstract}

Kata Kunci: Garam, Geomembran, Low Density Polyethylene

\section{A. PENDAHULUAN}

Garam merupakan komoditas penting yang banyak digunakan secara luas dari kepentingan konsumsi sampai dengan industri. Garam terdiri dari kumpulan senyawa kimia yang bagian utamanya merupakan senya Natrium Klorida $(\mathrm{NaCl})$ dengan zat-zat pengotor terdiri dari $\mathrm{CaSO} 4, \mathrm{MgSO} 4, \mathrm{MgCl} 2$ dan lainlain. Produksi garam di Indonesia pada umumnya menggunakan metode pengupan air laut dengan bantuan sinar matahari (Umam, 2019).

Proses pengerjaan pembuatan garam dilakukan pada musim kemarau, dimana lahan penguapan dialiri air laut dengan mesin pompa. Dilahan ini air diuapkan sehingga menjadi air tua. Air tua dialirkan kemeja 
kristalisasi dimana nanti air laut nanti akan menjadi kristal-kristal garam. Mutu garam dikendalikan dengan cara membuang atau memisahkan bitern, yaitu hanya mengkristalkan garam pada kepekatan $25^{\circ}-30^{\circ}$ Be. Kristal garam yang dipanen diangkut dan disimpan di gudang penyimpanan. Proses penjualan dapat dilakukan dengan pencucian atapun dengan langsung dijual sebagai garam curai. Garam yang dihasilkan berupa kristal putih selain mengandung $\mathrm{NaCl}$ juga mengandung mengandung garam lain yang merupakan impuritas. Pada waktu pengkristalan air laut dialirkan ke tambak-tambak, selanjutnya untuk menguapkan airnya akan terjadi pemekatanair laut secara bertahap (Rositiawati et. al. 2013).

Indonesia berpotensi untuk menjadi negara penghasil garam ini dikarenakan Indonesia memiliki garis pantai yang cukup luas. Namun potensi ini tidak di imbangi tidak diimbangi dengan jumlah dan mutu di Indonesia. Mutu dari garam Indonesia masih banyak yang tidak memenuhi SNI di lihat dari kadar $\mathrm{NaCl}$ nya, ini disebabkan bahan baku yang digunakan masih sangat rendah mutunya, proses refening yang tidak memenuhi syarat serta pengelolaan pabrik yang tidak profesional hal ini dapat dimaklumi karena industri garam masih sangat kecil. Kualitas garam yang dikelola secara tradisional umumnya harus dikelolah ulang untuk dijadikan garam konsumsi dan garam industri (Rositiawati et. al. 2013).

Kelurahan Talise merupakan kelurahan yang berada di Kecamatan Mantikulore Kota Palu Sulawesi Tengah. Kelurahan Talise merupakan satu-satunya keluruhan di Kota Palu penghasil garam karena daerahnya sebagian besar berada di pesisir teluk Palu. Masyarakat yang tinggal di wilayah pesisir teluk palu memiliki mata pencarian sebagai nelayan dan petani garam. Petani garam di Talise telah lama menekuni profesinya sebagai petani garam bahkan diantara mereka menekuni sejak masih kecil dan metode produksi garam yang digunakan masih metode yang diwariskan secara turun temurun (tradisional). Menurut Arwiyah et al. (2015) hasil garam khususnya garam rakyat yang dilakukan pada tambak dengan meja kristalisasi berupa tanah masih seringkali tercampur tanah dan proses pembuatannyapun dirasakan cukup lama. Oleh karena itu adanya teknologi baru dalam pembuatan garam sangat dibutuhkan agar kualitas dan hasil produksi garam meningkat. Pembuatan garam dengan media meja garam yang berbeda akan menghasilkan sejumlah garam dengan kualitas yang berbeda juga.

Produksi garam di Tambak Garam Talise mengunakan metode tradisional yang menyebabkan pola produksi garam cenderung statis, sehingga peningkatan produksi tidak signifikan dan kurang berkualitas. Rendahnya produktifitas dan kualitas garam tersebut mengakibatkan rendahnya harga yang diterima petani garam, kondisi tersebut jelas mempengaruhi kesejahteraan. Untuk mengatasi masalah ini perlu dilakukanya metode moderen seperti yang yang pernah dilakukan Yaqin dan Setiyani (2017) Produksi, biaya, penerimaan, pendapatan dan kelayakan finansial (R/C rasio) usaha tani garam menggunakan geomembran lebih besar dibandingkan usahatani garam secara tradisional.

Teknologi geomembran LDPE (Low Density Polyethylene) merupakan program pemberdayaan yang difokuskan pada peningkatan produksi dan kualitas produk garam serta peningkatan kesejahteraan dengan meningkatkan pendapatan petambak garam. Geomembran LDPE terbuat dari bahan yang tahan air dan menyerap panas sehingga proses kristalisasi akan lebih cepat.

Tujuan dari kegiatan ini yaitu menerapkan teknologi geomembran LDPE pada kelompok petani garam di Talise dalam memproduksi dan meningkatkan kualitas garam berstandar SNI sebagai garam konsumsi serta meningkatkan kesadaran petani garam untuk menggunakan teknologi dalam mengelola tambak garamnya. Kegiatan yang dilakukan pada program pengabdian ini dengan melakukan sosialisasi kegiatan kepada mitra untuk menentukan kegiatan yang dilaksanakan pada tahap selanjutnya dan memberikan pemaham akan pentingnya penggunaan teknologi dalam produksi garam. Selain itu, kegiatan yang dilakukan yaitu memberikan bantuan berupa plastik geomembran kepada mitra petani garam.

\section{B. PELAKSAAN DAN METODE}

Kegiatan Pemberdayaan Usaha Garam Rakyat pada kelompok petani garam di Kelurahan Talise Kota Palu dilaksanakan pada tanggal 30 Agustus sampai 10 November 2021. Pada kegiatan ini dilaksanankan dengan tiga tahap yaitu tahap pertama sosialisasi, tahap kedua pra produksi dan tahap ketiga yaitu tahap produksi garam (Ruslan et. al. 2020).

\section{Tahap Sosilisai}

Sosilisasi ini melibatkan perwakilan semua kelompok petani garam yang ada dikelurahan Talise yang berjumlah 12 kelompok, dengan melibatkan pemateri dari Dinas Kelautan dan Perikanan 
Provinsi Sulawesi Tengah. Kegiatan sosialisasi ini bertujuan untuk memberikan pengetahun kepada kelompok tani tentang teknologi geomembran LDPE, baik dari manfaat dan ke unggulan dari teknologi tersebut.

2. Tahap Praproduksi

Tahap praproduksi dilakukan dengan penyiapan lahan untuk percobaan penerapan teknologi geomembran LDPE yang dimulai dari penataan petak tambak, perataan tanah, pengeringan lahan tambak dan pemasangan pelastik geomembran. Kegiatan ini didampingi oleh pemateri dari BPSPL (Balai Pengelolaan Sumberdaya Pesisir dan Laut) Makassar. Tujuan tahap praproduksi yaitu mempraktekan langsung tentang tata cara pemasangan plastik geomembran LDPE di meja kristalisasi kepada kelompok petani garam.

3. Tahap Produksi

Tahap ini merupakan tahap akhir dengan melakukan penguapan air laut menjadi air tua dan mengalirkan ke meja kristalisasi dan proses pemanenan. Tahap ini nantinya akan diperoleh garam dari penerapan teknologi geomembran LDPE dari segi kualitan dan kuantitas garam yang dihasilkan. Tahapan ini terdiri dari:

a. Mengisi air laut menuju lahan penampungan air muda. Pengaliran air laut bisa menggunakan bantuan mesin pompa

b. Air laut dari saluran primer (caren) kemudian dialirkan ke petak penampung air muda kemudian di endapkan selama 7 - 10 hari dengan ketinggian air kurang lebih 1 meter dan kemiringan 1:1

c. Setelah itu air di alirkan ke petak peminihan I dengan kedalaman air kurang lebih $40 \mathrm{~cm}$. kemudian diendapkan agar terjadi penguapan sehingga kepekatan air dari $7^{\circ} \mathrm{Be}$ menjadi $10^{\circ} \mathrm{Be}$ dengan kemiringan lahan 1:1

d. Kemudian air di alirkan kembali ke petak peminihan II selama $2-4$ hari dengan kedalaman air kurang lebih $30 \mathrm{~cm}$ hingga kepekatan air meningkat dengan kemiringan lahan 1:1

e. Kemudian air di alirkan ke petak peminihan III dan di endapkan kembali selamah $2-4$ hari dengan kedalaman air kurang lebih $20 \mathrm{~cm}$ hingga kepekatan air makin meningkat dengan kemiringan lahan 1:1

f. Kemudian air di alirkan ke petak peminihan IV dan diendapkan kembali selama $2-4$ hari dengan kedalaman air kurang lebih $10 \mathrm{~cm}$ hingga mencapai kepekatan air $18^{\circ} \mathrm{Be}$ disini air tua siap untuk masuk petak kristalisasi dengan media geomembrane namun air dengan kepekatan 18 oBe belum bisa masuk petak kristalisasi untuk media tanah, karena untuk media tanah membutuhkan kepekatan air 21 oBe sehingga membutuhkan waktu pengendapan lebih lama pada petak peminihan IV dengan kemiringan lahan 1:1

g. Kemudian air yang memiliki kepekatan 18 oBe dialirkan kemeja kristalisasi yang dilapisi media geomembrane dengan kemiringan lahan 1:0,5 dan di lepas hingga menjadi garam dan umur 4 hari garam sudah dapat di panen. Proses ini dapat dilihat pada gambar 1.

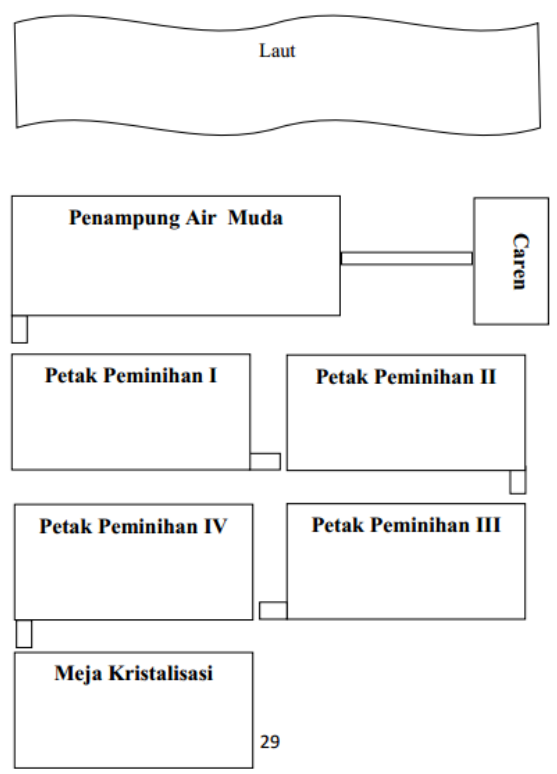

Gambar 1. Proses pembuatan garam 


\section{HASIL DAN PEMBAHASAN}

Kegiatan Pengabdian Kepada Masayarakat progam holistik pembinaan dan pemberdayaan desa (PHP2D) bertujuan untuk meningktkan produksi dan kualitas garam pada petani garam di Kelurahan Talise Kecamtan Mantikulore Kota Palu Sulawesi Tengah. Kegiatan ini diawali dengan kegiatan sosialisasi tentang manfaat dan keunggulan menggunakan teknik geomembran LDPE. Dalam kegiatan ini pemateri yang kami undang yaitu perwakilan dari Dinas Kelautan dan Perikanan Provinsi Sulawesi Tengah bisa dilihat pada gambar 2 .

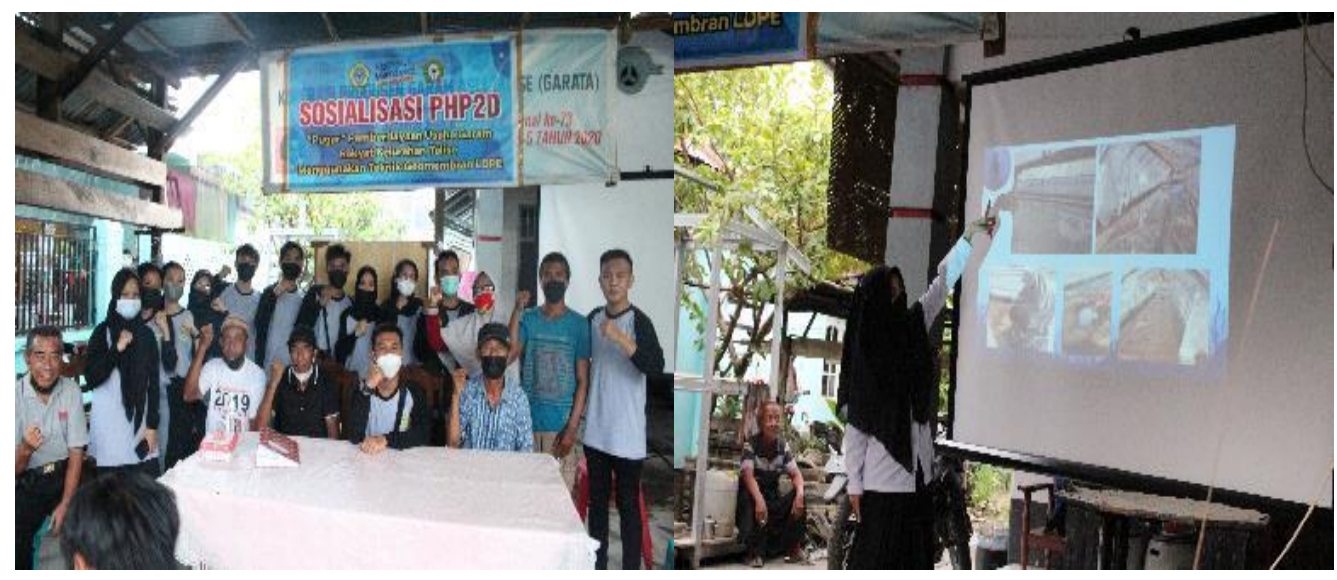

Gambar 2. Sosialisasi Teknologi geomembran LDPE

Dari hasil kegiatan sosialisasi ini kelompok tani sangat antusis dengan teknologi yang disosialisasikan. Penggunaan teknologi geomembran LDPE dapat meningkatkan kualitas garam yang diproduksi oleh mitra sehingga harga jual garam dapat ditingkatkan. Teknologi geomembran LDPE tidak hanya dapat digunakan 1 kali panen, namun bisa 4 kali pananen. Hal ini sesuai dengan yang dilakukan oleh Ruslan et. al. (2020) dari hasil kegiatan mereka diperoleh Penggunaan plastik geomembran dapat meningkatkan kualitas garam yang diproduksi oleh mitra sehingga harga jual garam dapat ditingkatkan. Disamping itu, penggunaan plastik geomembran dapat meningkatkan produksi lahan sehingga meningkatkan produktivitas lahan. Plastik geomembran tidak hanya digunakan pada satu musim panen, tetapi juga dapat digunakan sampai 4 kali masa panen.

Selama ini kelompok tani garam Talise Kota Palu tidak menggunakan teknlogi geomembran dikarenakan belum mengetahui manfaat langsung dari geomembran dan harga geomembran terbilang cukup mahal, untuk itu pada kegiatan ini kami juga membagikan plastik geomembran LDPE kepada kelompok petani garam. Sehinnga adanya bantuan ini kualitas dan harga jual garam dapat meningkat hasil garam dan petani garam di Talise juga sadar akan penerapan teknologi di tambak garam milik mereka merupakan hal yang sangat penting.

Produksi garam menggunakan teknologi geomembran LDPE dilakukan beberapa tahap. Tahap pertama yaitu dengan melakukan pembuatan meja kristal. Tahap ini diawali dengan megerikan meja kristal selama 2 minggu, dan meja kristal dibatasi dengan papan. Penggunaan papan ini bertujuan agar tanah pematang tidak jatuh lagi dimeja kristal yang telah dipasangi plastik geomembran. Proses ini dapat dilihat pada gambar 3 .

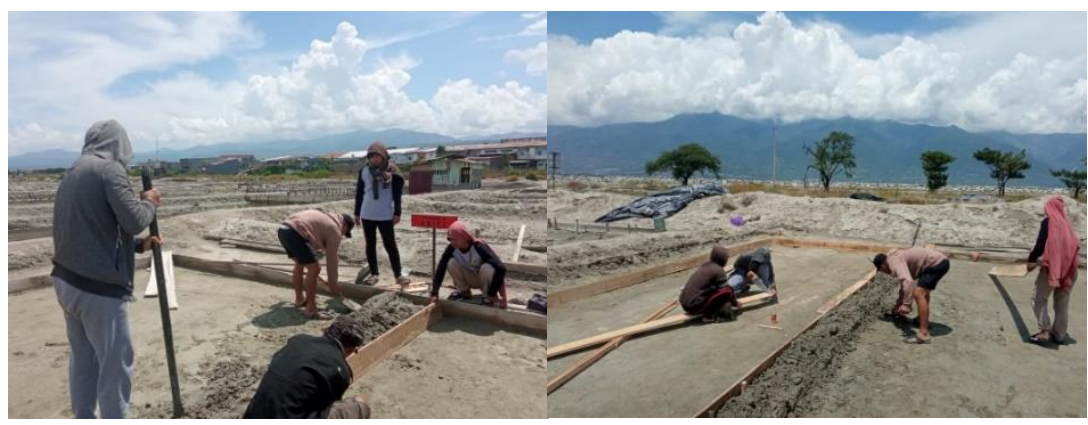

Gambar 3. Pembuatan meja Kristal 
Tahap selanjutnya yaitu dengan pemasangan plastik geomembran. Tahap ini dapat dilihat pada gambar 4.

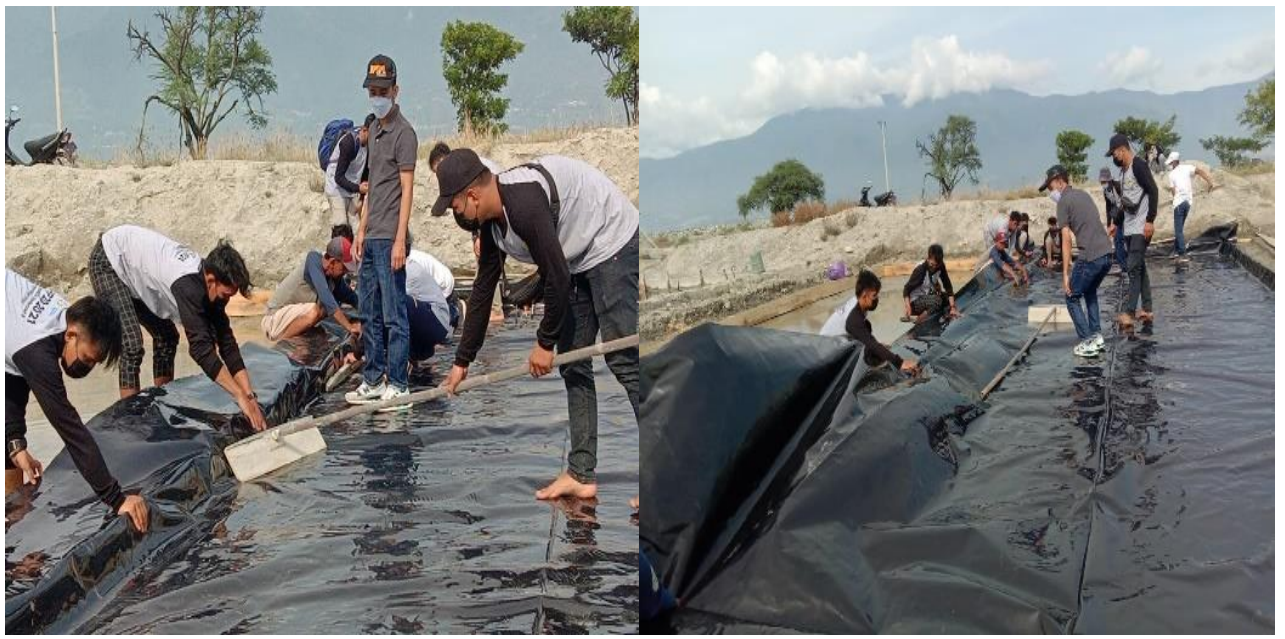

Gambar 4 Pemasangan Pelastik Geomembran LDPE

Pemasangan plastik geomembran LDPE dipasang pada pagi hari, dikarenakan pada saat pagi hari angin tidak terlalu kuat sehingga memudahkan saat membentangkan plastik geomembran. Menurut Abdullah dan Susandini (2018) Geomembran terbuat dari material yang sangat tahan terhadap bahan kimia, asam tinggi dan limbah sehingga sangat sesuai untuk aplikasi pelindung air, tanah terhadap berbagai macam limbah. Geomembrane memungkinkan ditempatkan pada areal yang bergeometri berlekuk - lekuk, dan mampu mengikuti kontur tanah yang tidak rata, seperti perbukitan, dan kolam. LDPE tersedia dalam permukaan halus maupun bertekstur dan juga tersedia dalam berbagai ketebalan.

Penggunaan teknologi ini memudah kelompok petani garam dalam mengumpulkan garam dan prosesnya lebih efisien dan efektif hal ini dikarenakan petani sudah tidak cemas garam yang mereka panen tidak tercampur dengan tanah lagi. Menurut Abdullah dan Susandini (2018) ada beberpa manfaat dari penggunaan geomembran pada tambak garam yaitu Penyerapan panas dari matahari lebih intens, sebagai akibat efek warna hitam pada bahan geomembrane, bahan baku pembuatan garam berupa air laut tidak mudah susut terserap kedalam dasar lahan tambak garam yang biasanya hanya berbentuk tanah yang dipadatkan, Waktu proses kristalisasi lebih cepat, sehingga efisien dari segi waktu produksi, Garam yang dihasilkan lebih putih dan bersih karena tidak terkontaminasi tanah dasar lahan tambak. Sedangkan tambak garam yang tanpa geomembran yaitu waktu proses kristalisasi lebih lama, air cepat susut karena terserap oleh pori - pori tanah, dan garam yang dihasilkan lebih kusam dan kurang bersih karena tercemar tanah.

Perbandingan hasil produksi garam dengan menggunakan metode konvensional dengan teknologi geomembran LDPE dapat dilihat pada gambar 4.

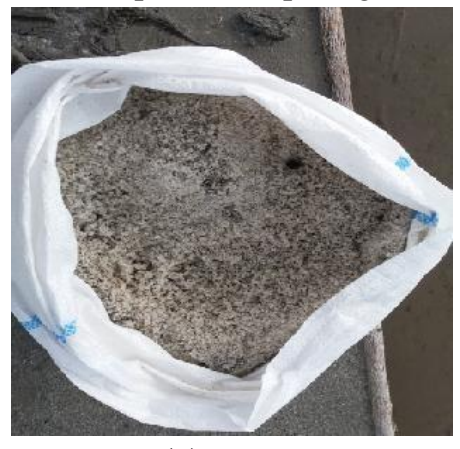

(a)

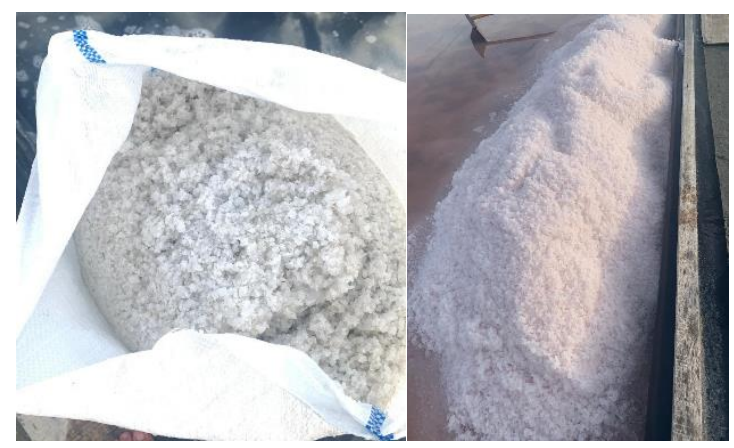

(b)

Gambar 4. (a) Garam menggunakan metode konvensional, (b) Garam menggunakan Teknologi Geomembran LDPE

Garam hasil panen petani garam Talise Kota Palu menggunakan teknik geomembran LDPE memiliki warna yang lebih putih dan bersih berbeda dengan metode konvensional yang terlihat berwarna kehitaman hal ini disebabkan garam yang menggunakan metode konvensional tercampur oleh tanah. Salin itu petani garam yang telah menggunakan teknik geomembran LDPE telah mengalami tiga kali peningkatan hasil panen dan waktu panennya lebih singkat 3 sampai 4 hari dibandingkan dengan metode konvensional memerlukan 7 sampai 8 hari. 
Menurut Abdullah dan Susandini (2018) kualitas garam terbagi menjadi 3 seperti dapat dilihat pada tabel 1 dibawah:

Tabel 1. Klasifikasi kualitas garam

\begin{tabular}{lll}
\hline Mutu/Kwalitas Garam & Kandungan Kimia & Pemanfaatan \\
\hline K.I (Baik Sekali) & NaCl $>95 \%$, sulfat, & Garam untuk industri kimia, \\
& magnesium dan kalsium, & industri aneka pangan, industri \\
& Cemaran Logam dll sangat & farmasi, industry perminyakan, \\
& kecil & pengolahan air NACl min 94\%, \\
& NaCl 90-95\%,kadar air 7\% & Garam konsumsi rumah tangga, \\
Kulfat, magnesium dan & industri makanan, industri \\
& kalsium sebesar 2\% & minyak goreng, industri \\
Cemaran Logam dll 1\% & pengasinan dan pengawaten \\
& ikan & Industri penyamakan kulit, \\
& NaCl 80-90\%, kadar air 7\% & Pengawetan dan Pengasinan \\
& sulfat, magnesium dan & \\
& kalsium sebesar 2\% & \\
& Cemaran Logam dll 1\% & \\
\hline
\end{tabular}

Berdasarkan pada tabel 4.1 dapat diketahui hasil garam yang diperoleh dari kegiatan pengabdian kepada masyarakat yang kami lakukan masuk pada mutu K.I (baik sekali) kami bedakan secara visual. Menurut Abdullah dan Susandini (2018) Untuk membedakannya

dapat dilakukan dengan melakukan uji laboratorium atau dapat juga dilihat secara visual yaitu :

1. Garam K.I secara visual ditunjukkan dengan warna putih bersih cenderung bening, butiran garam berupa kristal dengan ukuran minimal $0,5 \mathrm{~mm}$.

2. Garam K.II secara visual ditunjukkan dengan garam berwarna putih bersih namun agak kusam, butiran garam berupa kristal yang berukuran kurang dari $4 \mathrm{~mm}$.

3. Untuk garam K.III secara visual ditunjukkan dengan garam berwarna putih kusam, bercampur kotoran tanah, butiran garam berupa kristal yang berukuran kurang dari $3 \mathrm{~mm}$.

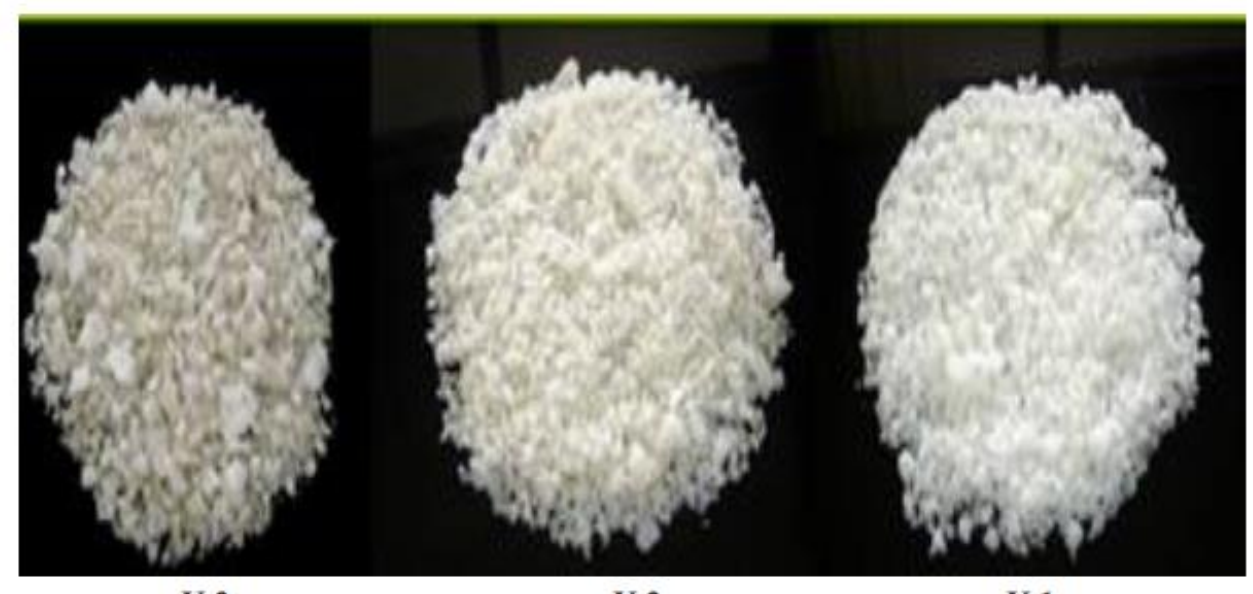

K.3

K.2

K.1

Gambar 5. Perbedaan kualitas garam

\section{PENUTUP}

\section{Simpulan}

Adapun kesimpulan yang dapat diambil dari kegiatan pengabdian kepada masyarakat ini yaitu:

1. Penggunaan teknologi geomembran LDPE pada meja kristal pembuatan telah meningkatkan kuantitas dan kualitas garam petani garam di Kelurahan Talise Kecamatan Mantikulore Kota Palu Sulawesi Tengah.

2. Peningkatan produksi garam menggunakan teknologi geomembran LDPE mencapai tiga kali lipat

3. Kelompok mitra petani garam di Kelurahan Talise Kecamatan Mantikulore Kota Palu Sulawesi Tengah dapat menerima dan telah bisa memasang plastik geomembran secara mandiri 


\section{Saran}

Saran yang dapat kami berikan yaitu pemerintah setempat mungkin bisa mensubsidikan plastik geomembran LDPE kepada mitra petani garam mengingat harga plastik geomembran sangatlah mahal untuk mitra.

\section{Ucapan Terima Kasih}

Penulis menyampaikan ucapan terima kasih kepada Direktorat Pembelajaran dan Kemahasiswaan yng telah memberikan dana hibah PHP2D tahun 2021.

\section{E. DAFTAR PUSTAKA}

Umam F. 2019. Pemurnian Garam dengan Metode Rekristalisasi di Desa Bunder Pamekasan untuk Mencapai SNI Garam Dapur. Jurnal Ilmiah Pengabdhi. 5 (1): 24-27.

Yaqin A, Setiani. 2017. Karakteristik Petani dan Kelayakan Finansial Usahatani Garam Secara Tradisional dan Teknologi Geomembran (Studi Kasus di Desa Pangarengan Kecamatan Pangarengan Kabupaten Sampang). Jurnal Pamator. 10 (1): 54-60.

Ruslan, Wiraningtyas A, Sandi A, Ariyansyah. 2020. Peningkatan Kualitas Garam Melalui Penggunaan Teknologi Geomembran Di Ikm Sanolo Jaya Desa Sanolo Kecamatan Bolo Kabupaten Bima. Aptekmas. 3 (4): 70-74

Rositiawati Al, Taslim CM, Soetrisnanto D. 2013. Rekristalisasi garam rakyat dari daerah Demak untuk mencapai SNI garam industri.Jurnal Teknologi Kimia dan Industri. 2(4):217-225.

Arwiyah, Zainuri M, Efendy M. 2015. Studi kandungan nacl di dalam air baku dan garam yang dihasilkan serta produktivitas lahan garam menggunakan media meja garam yang berbeda. Jurnal Kelautan. 8 (1): $1-9$. 